\title{
Experimental and Numerical Simulation of Desorption and Diffusion Process of the Adsorbed Gas in Coal Rock under Isothermal Conditions
}

\author{
Xiaohu Zhang $\mathbb{D}^{1,2}{ }^{1,2}$ Hi Li, ${ }^{2}$ Chunguang Wang, ${ }^{2,3}$ Zhifeng Zhao, $^{1}$ Lifeng Li, ${ }^{1,2}$ \\ and Xiao Wang ${ }^{4}$ \\ ${ }^{1}$ School of Civil Engineering, Guizhou University of Engineering Science, Bijie 551700, China \\ ${ }^{2}$ State Key Laboratory for Geomechanics \& Deep Underground Engineering, Beijing 100083, China \\ ${ }^{3}$ State Key Laboratory of Mining Disaster Prevention and Control, Shandong University of Science and Technology, \\ Qingdao 266590, China \\ ${ }^{4}$ School of Civil Engineering, Southeast University, Nanjing 211189, China
}

Correspondence should be addressed to Xiao Wang; x.wang@seu.edu.cn

Received 2 January 2021; Accepted 3 May 2021; Published 24 May 2021

Academic Editor: Shengnan Nancy Chen

Copyright (C) 2021 Xiaohu Zhang et al. This is an open access article distributed under the Creative Commons Attribution License, which permits unrestricted use, distribution, and reproduction in any medium, provided the original work is properly cited.

Investigation of desorption of diffusion migration of native adsorbed gas in coal under the action of temperature has always been one of the important directions of coal mine safety research. Five coal samples from the Sichuan Furong mining area are studied under the different isothermal conditions $\left(35^{\circ} \mathrm{C}, 30^{\circ} \mathrm{C}, 24.5^{\circ} \mathrm{C}, 36.2^{\circ} \mathrm{C}\right.$, and $\left.40^{\circ} \mathrm{C}\right)$ by means of laboratory tests; the desorption, diffusion, and migration processes of adsorbed gas were studied; the escaped gas volume in the process of diffusion, the escaped gas pressure, and the change of the concentration of the gas component content are summarized; and the emitted gas volume curve will be eventually found to be constant under the isothermal process. In addition, the escaped gas concentration showed a trend of increasing first and then decreasing. Based on the CT scan slice of coal samples, a network model of coal fracture based on the Tyson polygon contraction method is established in this paper, and LS-DYNA software is used to analyze the transient diffusion behavior of methane under three isothermal conditions $\left(24.5^{\circ} \mathrm{C}, 30^{\circ} \mathrm{C}\right.$, and $\left.42^{\circ} \mathrm{C}\right)$, and the experimental results are verified.

\section{Introduction}

Coal is one of the most important energy sources in the world; with the increasing shortage of shallow coal resources, more and more mines enter the mining depth of more than 1000 meters. With the increase in coal mining depth, along with the rise of geostress, the increase in water inflow, and the rise of ground temperature, the deep geological environment becomes more complex. Coupled with the strong mining disturbance caused by the deep mining [1-3], the sudden disasters of underground engineering are becoming more and more serious $[4,5]$.

Coal gas causes frequent and harmful disaster in mining engineering, and gas exists in the coal body in the form of a free state and adsorption state. The free gas is mainly distrib- uted in the big pores and cracks in the coal body. Adsorbed gas can be divided into two types: one is adsorbed on the surface of the gap and the other is in the form of solid solution between coal molecules or crystals [6-9]. With the increase in depth, the total specific pore volume of coal tends to decrease. Generally speaking, the proportion of large voids in the total void volume decreases with the increase in depth, while the proportion of microvoids increases significantly, and the total specific surface area increases significantly, which indicates that the deep coal can absorb more gas.

Gas and coal body in the natural coal seam exist in a balanced state. When the coal seam is mined, the original stress state of coal rock changes and the initiation of new cracks leads to the desorption and diffusion of gas from the coal seam to the goaf. At the same time, with the increase in 
mining depth, because the metamorphic process of deep coal is larger, the total amount of generated gas is more than that of the shallow coal. Therefore, more and more scholars pay attention to the gas adsorption and desorption process [1015]. For example, Wang et al. [16-19] adopted the orthogonal test to research the influence degree of particle size, temperature, pressure, moisture content, and molding pressure on the coal gas desorption capacity, and the sensitivity of five factors was used to conduct regression analysis. To research the energy variation rules in the process of gas adsorption and desorption in coal, the adsorption-desorption experimental device was used by Gao et al. [20], and six coal samples of various particle sizes under different pressure conditions were evaluated. Based on the essence of the physical adsorption of methane, the effects of the critical moisture content and liquid water on methane adsorption and desorption were studied, providing instructions for the comprehensive control of gas in high-gas mines [21-24]. To accurately calculate the amounts of lost gas from coal, through the mercury intrusion porosimetry method (MIP), $\mathrm{CO}_{2}(273 \mathrm{~K})$ adsorption methods, and gas adsorption equilibrium tests, the effects of pore structure and the gas diffusion properties on the lost gas from tectonic and intact coals were investigated by Wang et al. [14]. Jin et al. [25] developed a new apparatus to carry out simulated experiments with different gases of $\mathrm{CO}_{2}$ and $\mathrm{N}_{2}$, the formation and transport mechanism of outburst coal-gas flow in the roadway was researched, and the effects of gas desorption on its development were evaluated. A gas desorption and diffusion experimental system was adopted to conduct isothermal methane gas desorption and diffusion experiments, and $\mathrm{Li}$ et al. [26] built a new mathematical model for gas diffusion in coal particles to calculate the diffusion coefficient. Based on the high/low temperature pressure swing adsorptiondesorption experimental system, a mathematical expression of the fixed-size desorption index $(K-1)$ was established by Li et al. [27], and the effects of gas pressure, loss time, coal particle size, and diffusion coefficient on $K-1$ are studied.

With the increase in the buried depth, the temperature of deep coal increases linearly, and the conventional geothermal gradient is $30^{\circ} \mathrm{C} / \mathrm{km}$. When the temperature exceeds the normal temperature, the mechanical and deformation characteristics of the coal rock are quite different from those of the ordinary environment. Moreover, the rise of temperature also leads to the faster diffusion of gas in the deep coal body; thus, it is imperative to research the influence of temperature on the gas desorption process [28-31]. Considering the influences of gas pressure, temperature, and coal porosity, a coupled thermal-diffused-mechanical model for gas desorptiondiffusion under nonisothermal conditions was built by Liu et al. [32], and the gas desorption-diffusion tests were carried out on coal powder under isothermal and adiabatic conditions. Based on the coal oxidation heating system and the hightemperature and high-pressure gas adsorption instrument, $\mathrm{Xu}$ et al. [33] carried out the experiments to research the optimum oxidation temperature of coalbed for promoting methane desorption. The coal samples were prepared for desorption experiments with methane and nitrogen, the curves of desorption pressure and temperature were obtained, and a theoretical model of the desorption pressure and temperature in the system considered was established based on the Boltzmann energy distribution law [34].

Because the desorption and diffusion behaviors of adsorbed gas in raw coal under the coupled conditions of temperature and pressure are the questions that we are concerned about, the selected coal samples are not sealed, so that the free gas in the cracks can be diffused into the air. Under these conditions, only adsorbed gas remains in the coal. The diffusion process of adsorbed gas in the process of temperature-rising and constant temperature procedures is studied experimentally, the diffusion coefficient of the coal sample is calculated by combining the diffusion function, and the diffusion process of adsorbed gas in coal at engineering temperature is analyzed by numerical modeling. It provides a theoretical guidance for gas prevention and control in deep coal mining engineering.

\section{Gas Desorption Experiment and Analysis}

2.1. Experiment Equipment. Given the deep coal with many characteristics compared to the shallow coal body, the influence of temperature and pressure on the physical and mechanical properties of the coal matrix is stranger. Meanwhile, it has a large specific surface area which could adsorb more coal gas. In order to study the adsorbed coal gas' desorption and migration rule under the coupling of the temperature and pressure process, the deep temperature and pressure coupling test system of the Stay Key Laboratory For Geomechanics and Deep Underground Engineering was used to recreate the desorption and diffusion migration process of original adsorbed coal gas under constant temperature conditions. For the desorbed gas, the test system can also measure the pressure of the escaping gas, the volume of the escaping gas, the composition of the escaping gas, and the percentage concentration of their components.

The experimental system consists of five subsystems, namely, the host system, the servo control system, the temperature control system, the gas composition detection system, and the metering system, as shown in Figure 1. The host system includes the axial system (pump 1) and the lateral system (pump 1). The axial loading system is composed of the main engine and the axial hydraulic system. The axial loading system is called the XTYE-2000 hydraulic pressure testing machine, which can realize the functional purpose of applying axial pressure on the sample. The lateral pressure system applies oil pressure in the pressure chamber to achieve the function of circumferential pressure applied to the coal sample. The axial strain and radial strain are, respectively, monitored by the axial strain gauge (4) and the circumferential strain gauge (5) mounted on the surface of the sample. The temperature control system including the temperature controller (heating controller), the temperature sensor (3) and (6), and the electric heating device (1) can realize the automatic control of the oil temperature function to control the temperature control system, and the temperature controller adjusts the current in the electric heating device according to the monitoring data of the oil temperature by a sensor (3) and then implements the accurate control of hydraulic oil in the pressure chamber (precision of 


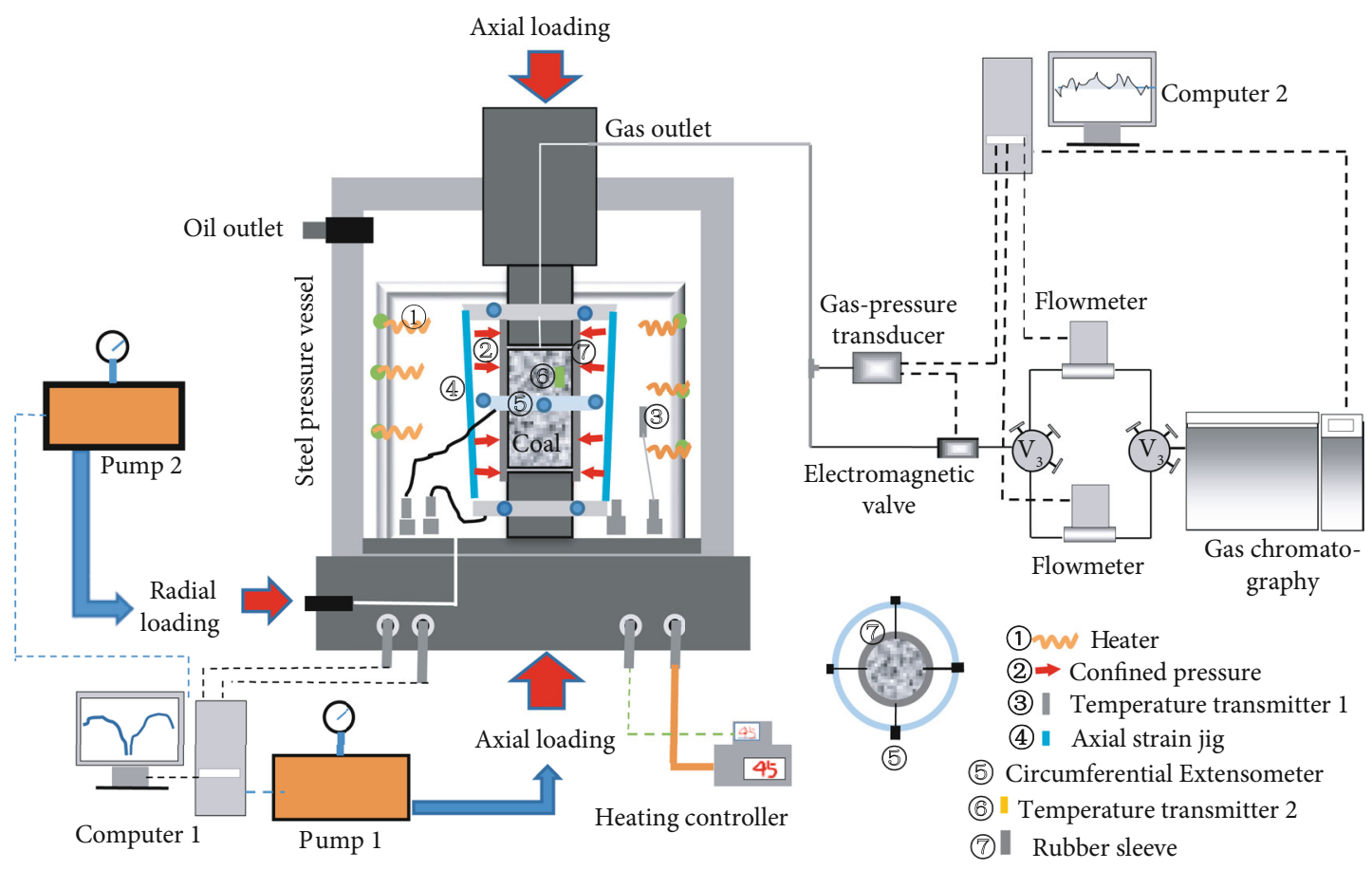

FIgURE 1: Schematic diagram of the experimental system.

plus or minus $0.1^{\circ} \mathrm{C}$ ). The other temperature sensor is directly attached to the surface of the sample to monitor the temperature changes of the coal sample itself during the heating process and adjust the temperature according to the experimental requirements. The sample and sensor (6) are sealed with rubber (7) to prevent oil from entering the sample and affecting the test. The composition of the gas monitoring system and the triaxial pressure chamber are connected via a catheter (gas outlet), and the gas monitoring system mainly includes the all-in-one machine of nitrogen and hydrogen and the gas chromatograph (gas chromatography). The chromatograph uses a series of thermal conductivity detector (TCD) with hydrogen flame detector (FID) methods for testing, and it can detect the main components of desorbed gas of coal samples and make automatic analysis of the respective content of gas composition. The gas measuring system includes a highly sensitive gaspressure sensor (measurement range of $-1000 \mathrm{~Pa} 1000 \mathrm{~Pa}$ ) and two gas flowmeters with different ranges (the working range of the flowmeter with a low range is $0 \sim 5 \mathrm{ml} / \mathrm{min}$, and that with a high range is $0 \sim 50 \mathrm{ml} / \mathrm{min}$ ). In this way, the parameter information of gas composition, content, pressure, and flow rate can be obtained during the experiment.

2.2. Experiment Procedure. Because the experiment only studies the appearance of desorption diffusion migration of adsorbed gas in raw coal under constant temperature, it only takes the influence of temperature into consideration. The specific experimental steps are as follows:

(1) Paste the temperature sensor on the surface of the coal sample with silica gel and fix it with an adhesive tape. Draw out the wiring from the holes reserved in the middle of the rubber sleeve and then weld a tem- perature sensor with the control line. The coal sample was then packed into the high-temperature resistant fluororubber sleeve, and the pores between the upper and lower pads and the rubber sleeve and the holes in the middle of the rubber sleeve were sealed with silica gel. Put the coal sample into the pressure chamber

(2) Connect the oil temperature conductor and coal temperature conductor with the temperature controller. Connect the electric heating wire to the temperature controller

(3) Check the chromatograph, connect the chromatograph with the standard gas tank, continuously detect the standard gas, and compare the concentration detection results with the standard concentration; if the difference between the two means that the chromatograph is in good working condition, the test then can continue

(4) Connect the chromatograph to the inlet at the upper end of the pressure chamber. Connect the flowmeter and the chromatograph. Turn on the temperature controller and chromatographic workstation and adjust their time to the same

(5) Set the temperature target value and raise the temperature. Maintain the temperature when the target temperature is reached. Check the composition of the gas every half an hour

(6) Stop the test

2.3. Experiment Sample. The selected coal mass blocks were taken from the Baijiao Coal Mine in Sichuan Province. Five 


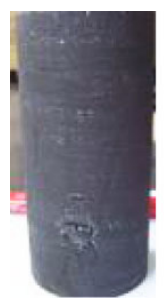

FR-1\#

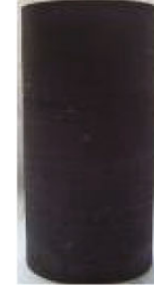

FR-4\#

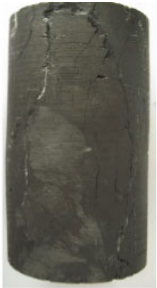

FR-5\#

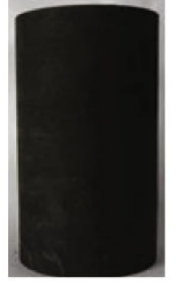

FR2-1\#

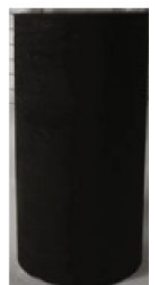

FR2-2\#

Figure 2: Furong samples before T-P coupling tests.

coal masses were firstly packed and then posted to the lab immediately after they had been taken. The five coal samples are from the four coal masses at the same working face of no. 2422. According to the recommended method of the International Society of Rock Mechanics [35], the processed coal sample size is $\phi 50 \times 25 \mathrm{~mm}$ and was made by using a drill machine and double-disc grinding machine in the lab, and the samples' roughness was controlled less than $\pm 0.05 \mathrm{~mm}$, the error of diameters was controlled less than $0.3 \mathrm{~mm}$, and the deviation of the perpendicularity between the section and the axis of the specimen is controlled less than $0.25^{\circ}$.

The Baijiao Coal Mine in the Furong mining area of Sichuan belongs to the Paleozoic Permian Basaltic formation, and the coal is anthracite. The mining area is located in the contact zone of the Sichuan Basin and Yunnan-Guizhou Plateau, and the terrain is high in the south and low in the north. The well field is located at the west end of the secondary fold of the long-double anticline-the south wing of the Shuanghe anticline. Except for some small wavy undulations, it is basically a monoclinal structure with a gentle dip, with a general inclination of $200 \sim 230^{\circ}$ and a dip angle of $7 \sim 26^{\circ}$, which increases gradually from west to east. The coal measure strata in this mine field have poor gas permeability, and the structure is a gently inclined monoclinal structure. The gas content of the coal seam is relatively high, and the spontaneous combustion of the coal seam will also occur in this coal seam, which is a high-gas mine. The coal sample is taken from the machine lane of the 2442 working face of the mine. The coal body strength of the working face is low, and there will be a sharp increase and sudden release of energy, so that the coal body outburst and gas outburst occur frequently. A total of 5 samples were made, as shown in Figure 2. In order to ensure the accuracy of the experimental results, measures are taken from three aspects. First, the sample preparation process is strictly controlled to ensure the flatness of the coal sample, so that the tight contact between the coal sample and the seal is achieved. Secondly, the coal samples were placed for at least one month so that free gas could be diffused into the air in advance, while only adsorbed gas was retained in the coal samples. Thirdly, the samples are sealed as well as the wires and the gas pipelines so that the monitored gas is the migration and diffusion of adsorbed gas in the coal body.

Table 1 gives the basic physical parameters of the test samples and some basic information of the experiment process.

2.4. Experiment Results. Figures 3-5 show the correlation curves of desorption and diffusion of coal samples 1-1\#, 1$4 \#$, and 1-5\# under constant temperature conditions, respec-
TABLE 1: Basic parameters of coal samples from each mine.

\begin{tabular}{lccccc}
\hline $\begin{array}{l}\text { Sample } \\
\text { number }\end{array}$ & $\begin{array}{c}\text { Diameter } \\
(\mathrm{mm})\end{array}$ & $\begin{array}{c}\text { Height } \\
(\mathrm{mm})\end{array}$ & $\begin{array}{c}\sigma_{c} \\
(\mathrm{MPa})\end{array}$ & $\begin{array}{c}\text { Temperature } \\
\left({ }^{\circ} \mathrm{C}\right)\end{array}$ & $\begin{array}{c}E \\
(\mathrm{GPa})\end{array}$ \\
\hline FR1-1\# & 50.42 & 99.70 & 19.46 & 35 & 3.33 \\
FR 1-4\# & 50.20 & 100.80 & 20.15 & 30 & 3.10 \\
FR 1-5\# & 50.34 & 99.70 & 20.15 & 24.5 & 3.10 \\
FR2-1\# & 50.28 & 99.72 & 9.53 & 36.2 & 1.64 \\
FR2-2\# & 49.44 & 100.02 & 10.76 & 42 & 1.34 \\
\hline
\end{tabular}

tively. It can be seen from Figure 3(a) that the pressure of the escaped gas fluctuates around 0 without a large peak. The volume of the escaped gas rises the fastest at the moment of $0 \mathrm{~min}$ and then slowly increases until it reaches the level with a maximum value of $1.055 \mathrm{ml}$ after $70 \mathrm{~min}$. It can be seen that the concentrations of the three components first increased and then decreased; the minimum value occurred at $6.5 \mathrm{~min}$, the magnitude of which was $5.60 \%, 0.437 \%$, and $0.00479 \%$; the maximum values occurred at $49.51 \mathrm{~min}$, of which the values were $6.30 \%, 0.799 \%$, and $0.006 \%$; and the concentrations at the end of the experiment were $6.11 \%$, $0.785 \%$, and $0.00578 \%$, respectively.

Figure 4(a) corresponds to a relatively short time period of the constant temperature process, and the volume of escaping gas is relatively larger than that of the other samples, which reaches a maximum of $2.87 \mathrm{ml}$ but does not reach the desorption equilibrium state. In addition, it can be seen that the pressure of escaping gas appears to have three small peaks, which were $16 \mathrm{~Pa}$ at $9.6 \mathrm{~min}, 16 \mathrm{~Pa}$ at $46.7 \mathrm{~min}$, and $58 \mathrm{~Pa}$ corresponding to $94.6 \mathrm{~min}$. The flow curve at the corresponding position also shows a jump growth, indicating that the positive pressure of escaping gas corresponds to a sharp increase in the volume of escaping gas. It can be seen from Figure 4(b) that there is no ethane in the composition, and the concentration curves of methane and carbon dioxide show a linear trend of growth. The minimum value occurs at $0.88 \mathrm{~min}$, and the values are $0.279 \%$ and $0.1476 \%$, respectively. The maximum value occurs at the end time, and the values are $0.352 \%$ and $0.2357 \%$, respectively.

Figure 5(a) shows that the maximum value of the escape gas pressure exceeds $100 \mathrm{~Pa}$, and within $20 \mathrm{~min}$, five positive pressures over $20 \mathrm{~Pa}$ occur, resulting in a sharp increase in the volume curve of the escape gas at these positions. In addition, the pressure of the escape gas reaches $50 \mathrm{~Pa}$ at $35.5 \mathrm{~min}$ and $76.3 \mathrm{~min}$, and the maximum amount of escape gas is $1.3 \mathrm{ml}$. It can be seen from the concentration curve that the 

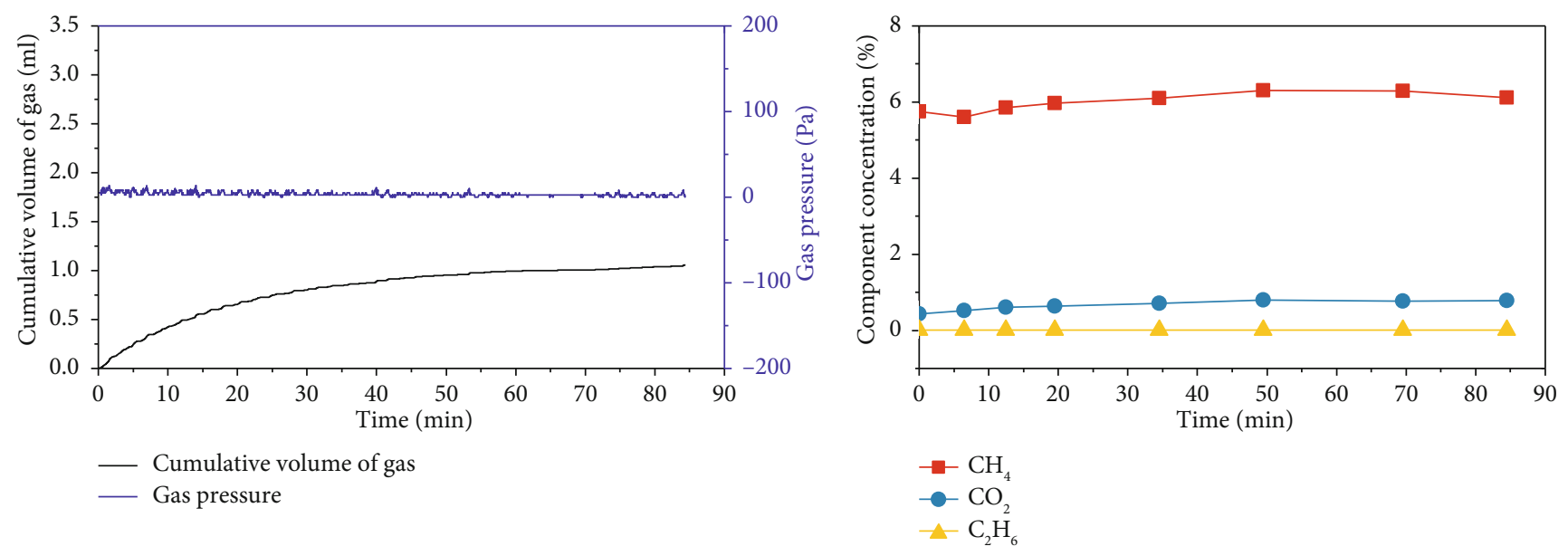

(a)

(b)

Figure 3: Experimental curves of Furong sample 1-1\# for T-P coupling tests.

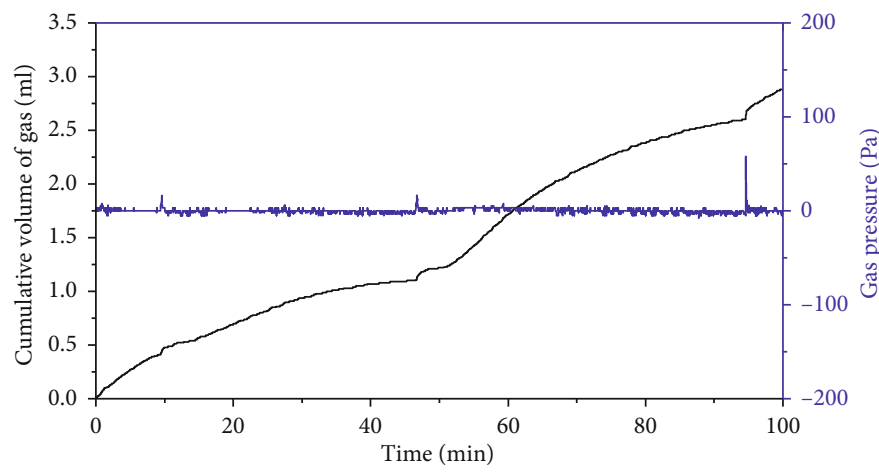

- Cumulative volume of gas — Gas pressure

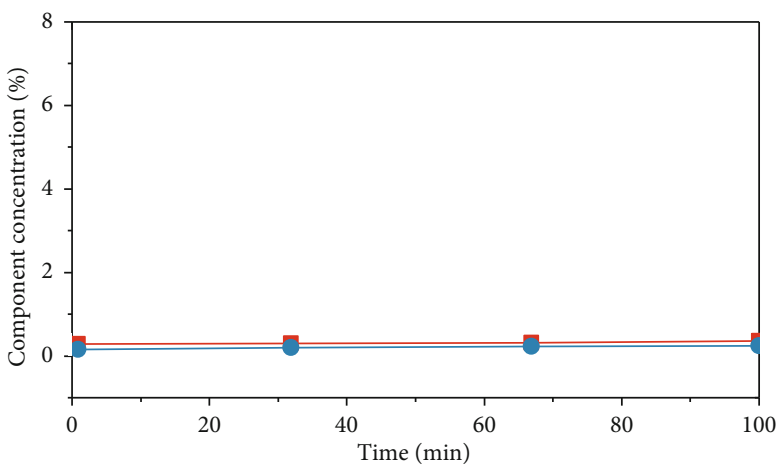

$-\mathrm{CH}_{4}$

$\mathrm{CO}_{2}$

(a)

(b)

Figure 4: Experimental curves of Furong sample 1-4\# for T-P coupling tests.

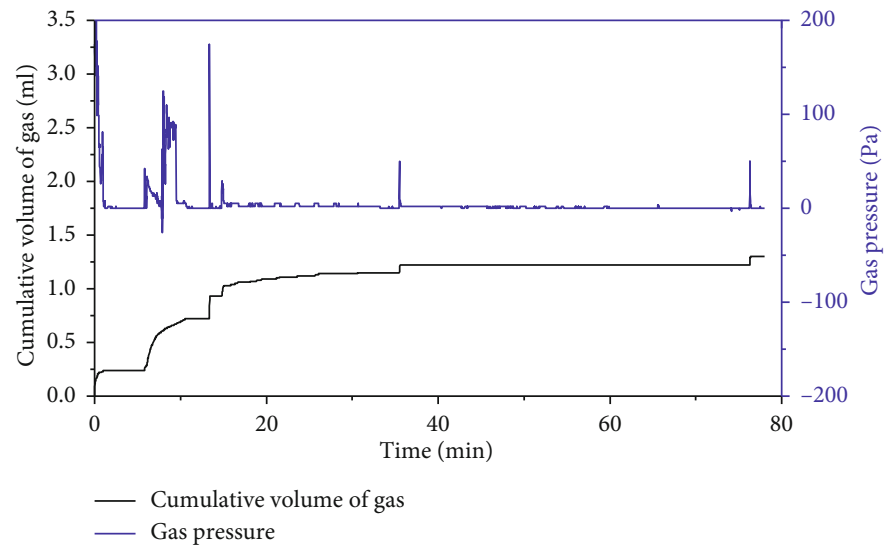

(a)

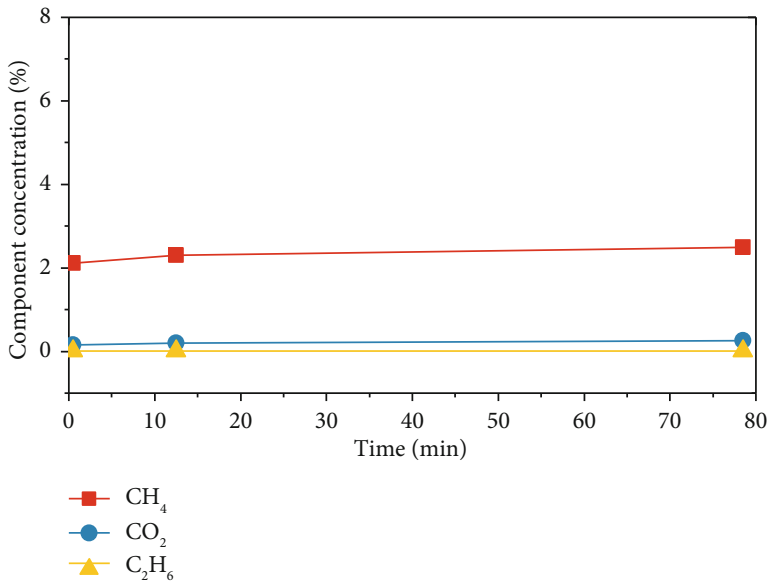

(b)

FIgURE 5: Experimental curves of Furong sample 1-5\# for T-P coupling tests. 
three gases methane, carbon dioxide, and ethane are all present, and the concentration curve shows an increasing trend. The minimum value is $2.1 \%, 0.15 \%$, and $0.015 \%$, respectively, and the maximum value is $2.50 \%, 0.253 \%$, and $0.014 \%$, respectively.

Figures 6 and 7 correspond to the constant temperature test curves of coal samples 2-1\# and 2-2\# in the Furong mining area, respectively. It can be seen from Figure 6(a) that between $36.4 \mathrm{~min}$ and $44.7 \mathrm{~min}$, the gas pressure appeared to be more than $50 \mathrm{~Pa}$, and the amount of the gas evolution curve also increases at the corresponding position; the measure of the escaped gas is $2.12 \mathrm{ml}$. It can be seen in Figure 6(b) that methane concentration increases first and then decreases, and the maximum value is $3.39 \%$, which occurred at $21.0 \mathrm{~min}$; the minimum value occurred in the initial stage, the figure was $2.93 \%$, and ethane and carbon dioxide levels are much smaller; the largest carbon dioxide levels occurred at the end of the experiment, the figure was $0.345 \%$, and ethane's maximum value is $0.010 \%$ and happened in $21.0 \mathrm{~min}$. Figure 7 (a) shows that the volume curve of the escaped gas rose steadily and finally reached $2.57 \mathrm{ml}$. The concentration curve also showed a trend of increasing first and then decreasing. The maximum value occurred in $70 \mathrm{~min}$, and the corresponding concentrations of the three components were $0.864 \%, 0.348 \%$, and $0.0014 \%$, respectively. The minimum values were $0.725 \%, 0.241 \%$, and $0.0012 \%$, respectively, which occurred at the beginning of the experiment.

In a word, although these 5 samples are all from the same mining area and same location, they show different properties in different isothermal experiments. The escaped gas quantity does not increase in accordance with the increase in temperature, but the sample at $30^{\circ} \mathrm{C}$ has the largest volume of escaped gas, followed by the sample at $42^{\circ} \mathrm{C}$, and the minimum escaped gas volume corresponds to the sample at $35^{\circ} \mathrm{C}$. Therefore, the individual difference of coal samples is an important factor affecting the sample results, but a conclusion is drawn; in the isothermal process, the desorption component concentration meets the rule of increasing first and then decreasing.

\section{Model Establishment and Verification}

3.1. Coal Rock Model Establishment. Figure 8(a) shows a common surface of coal fractures, while Figure 8(b) gives the coal damage fracture distribution information of a CT scan slice. It can be seen from the chart that the fissure distribution was compared with the polygon form, so an appropriate polygon transformation can be used to build a coal fracture pore model.

The Voronoi diagram, also known as the Dirichlet mosaic, was first proposed by Dirichlet in 1850 and then simplified by Russian mathematician Voronoi. In 1911, it was used by Dutch climatologist A.H. Hiessen to divide the effective regions of meteorological observation stations [34]. Simply, the Voronoi diagram is a partition of the plane, whose control point set $P=\left\{P_{1}, P_{2}, \cdots, P_{n}\right\}$, any two points are not colocated, and any four points are not cocircular. In any convex polygon (Tyson polygon), the distance from any inner point to the control point $P_{i}$ of the convex polygon is less than the distance from the point to any other control point $P_{j}$. Figure $8(\mathrm{c})$ shows the Tyson polygon example generated by the 50 control points. If the Tyson polygon itself is solid, the fissure channel is formed by the separation of polygons from polygons. Since the distance between the boundaries of the Tyson polygon established by the above method is 0 , cracks cannot be formed in the process of modeling. Therefore, cracks must be generated between the particles by means of polygon contraction inward. In this chapter, a polygonal inward shrinkage method is used to analyze the variation of porosity with different similar shrinkage rates.

The principle of polygon contraction is as follows:

$$
P_{i}^{\prime}(x, y)=P_{i}(x, y)-P_{0}(x, y),
$$

where $P_{i}^{\prime}(x, y)$ is the coordinates of the migrated polygon, $P_{i}$ $(x, y)$ is the initial coordinates, and $P_{0}(x, y)$ is the offset value. And the above three parameters are all matrices, as shown in Figures 9(a) and 9(b), which are the variation curves of porosity calculated at different shrinkage rates.

3.2. Selection of Gas Diffusion Coefficient in Coal Rock. Coal is a very complex porous medium, which has a dual pore structure. The migration of methane in the pore of the coal seam includes three processes: desorption, diffusion, and seepage. When the coal seam enters the deep underground, the ground temperature rises gradually, and the gas diffusion rate in the high-temperature coal body is very fast. At present, the experiment studies the gas adsorption and diffusion behavior of coal under the condition of an external gas source. However, the numerical value of the adsorption gas diffusion coefficient of the raw coal is still difficult to estimate, so it can be used to estimate the adsorption gas diffusion coefficient of the original coal from the data of the isothermal test.

Since diffusion is the main form of mass transfer in coalbased particles and fractures, it is assumed that the pores of particles are uniform and the transfer resistance is stable. Assuming that the diffusion coefficient is independent of the practice, then it can be seen that the diffusion process obeys the second law of Fick, and the diffusion differential equation in spherical coordinates is as follows:

$$
\frac{\partial c}{\partial t}=D\left(\frac{\partial^{2} c}{\partial^{2} r}+\frac{2 \partial c}{r \partial r}\right) .
$$

It is easy to know that $D$ is the diffusion coefficient $\left(\mathrm{cm}^{2} / \mathrm{s}\right), C$ is the concentration of diffusion fluid $\left(\mathrm{g} / \mathrm{cm}^{3}\right)$, and $R$ is the polar radius $(\mathrm{cm})$. When initial conditions and boundary conditions are given, the analytic solution of the above differential equation is as follows:

$$
\frac{Q_{t}}{Q}=1-\frac{6}{\pi^{2}} \sum_{n=1}^{\infty} \frac{1}{n^{2}} e^{-n^{2} \pi^{2} D_{e} t}
$$

$D_{e}=D / t$ is defined here, in which $Q_{t}$ is the accumulated diffusion amount $\left(\mathrm{cm}^{3}\right)$ at time $t, Q$ is the maximum value in the diffusion process, and $D_{e}$ is the diffusion rate of 


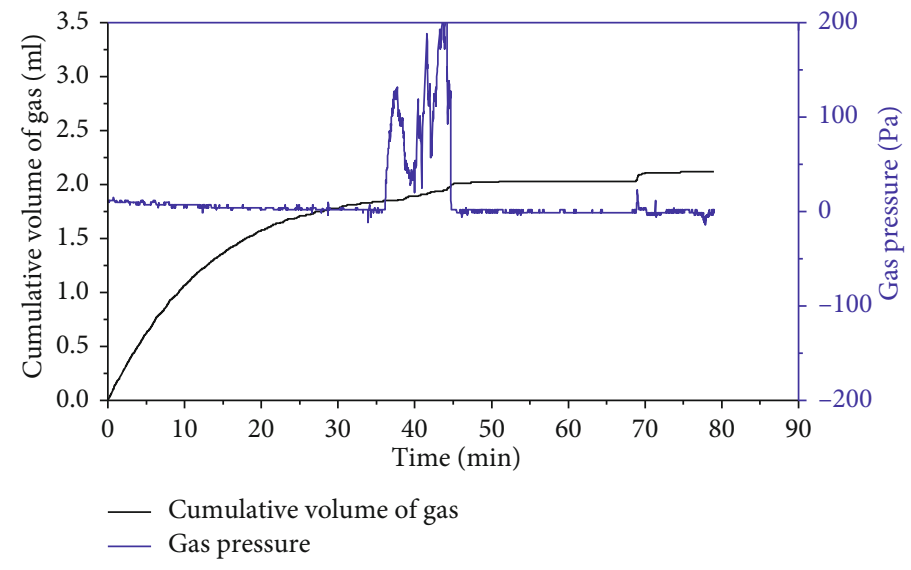

(a)

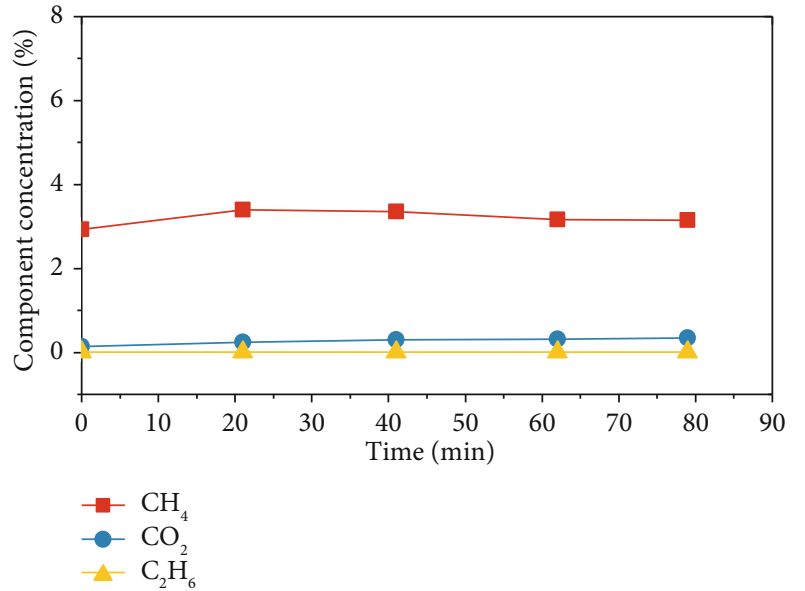

(b)

FIgURE 6: Experimental curves of Furong sample 2-1\# for T-P coupling tests.

methane in coal matrix particles. Reference [20] obtained the following relationship through numerical simulation of equation (3).

$$
\frac{Q_{t}}{Q}=\sqrt{1-e^{-\pi^{2} D_{e} t}}
$$

Because the diffusion percentage is equal to the desorption percentage of the methane diffusion process in the coal matrix, then

$$
\frac{Q_{t}}{Q}=\frac{V_{t}}{V},
$$

where $V_{t}$ is the cumulative desorption $\left(\mathrm{cm}^{3}\right)$ at time $t$ and $V$ is the maximum desorption in the diffusion process. So equation (5) goes into equation (4). Taking the natural logarithm of the expression, then

$$
\frac{-\ln \left[1-\left(V_{t} / V\right)^{2}\right]}{\pi^{2}}=\Phi(t)=D_{e} t .
$$

Therefore, $D_{e}$ can be obtained by fitting the experimental data. Since $D_{e}=D / t$, the comprehensive diffusion coefficient $D$ can be obtained. Take TM1-1\#, TM1-4\#, TM1-5\#, TM2$1 \#$, and TM2-2\# of the Furong Baijiao Coal Mine as examples to calculate their diffusion coefficient. Assume that the average diameter of coal particles is $0.2 \mathrm{~mm}$. And according to $D=1.2 D_{e}$, Table 2 shows the calculation results of relevant diffusion parameters of coal samples selected in the Furong coal mine.

3.3. Model Verification. Because most diffusion processes are unsteady, the unsteady diffusion process requires Fick's second law to calculate. The change in concentration over time is equal to the value of the change in diffusion flux over distance $x$ :

$$
\frac{d C}{d t}=\frac{\partial}{d x}\left(D \frac{d c}{d x}\right)
$$

where $D$ is the diffusion coefficient $\left(\mathrm{m}^{2} / \mathrm{s}\right)$ and $C$ is the volume concentration of the diffused substance $\left(\mathrm{kg} / \mathrm{m}^{3}\right) . d C / d x$ is the concentration gradient, and $t$ is the diffusion time. If diffusion coefficient $D$ is independent of concentration, equation (6) can be written as

$$
\frac{d C}{d t}=D \frac{\partial^{2} c}{\partial x^{2}}
$$

Then, by substituting the initial conditions and convenience conditions, the partial differential equation of equation (8) above can be solved, and the concentration distribution, concentration gradient distribution, and diffusion flux at each moment can be obtained.

$$
C \frac{\partial \theta}{\partial t}=k \frac{\partial^{2} \theta}{\partial x^{2}}
$$

Equation (9) gives the form of a differential equation of the transient heat conduction equation, due to the mathematical similarity in the form between the transient heat conduction equation and Fick's second law of diffusion coefficient differential equations, so the method of solving the heat conduction equation can be used to solve the unsteady diffusion equation.

This model is based on the physical and mechanical conditions of gas-bearing coal in the T-P coupling test system of the deep coal sample. In order to restore the real experimental conditions, due to the sampling process and shipping process, the adsorbed gas of the shallow surface has spread into the air, and the test cannot destroy the pore fissure structure for the simple isothermal condition, so this article assumes that under the effect of temperature, the gas is mainly spread through the pore channels and can only be spread in the connected channels. The diameter and height of the real coal samples are $50 \mathrm{~mm}$ and $100 \mathrm{~mm}$, respectively. In the simulation, we selected a two-dimensional section of $50 \times 100 \mathrm{~mm}^{2}$ as the research object, and the equivalent porosity of the coal rock sample is $26.24 \%$. Since the coal sample is taken from the same site, it is considered that the porosity of all samples 


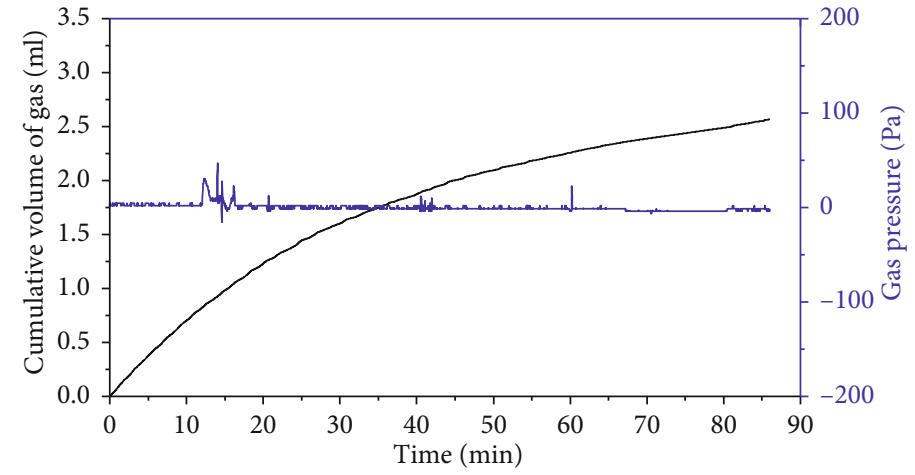

- Cumulative volume of gas - Gas pressure

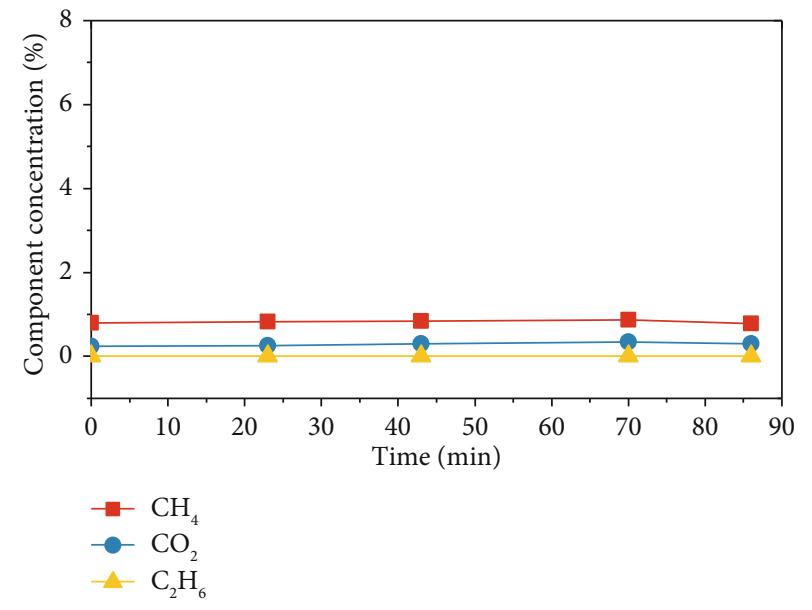

(b)

Figure 7: Experimental curves of Furong sample 2-2\# for T-P coupling tests.

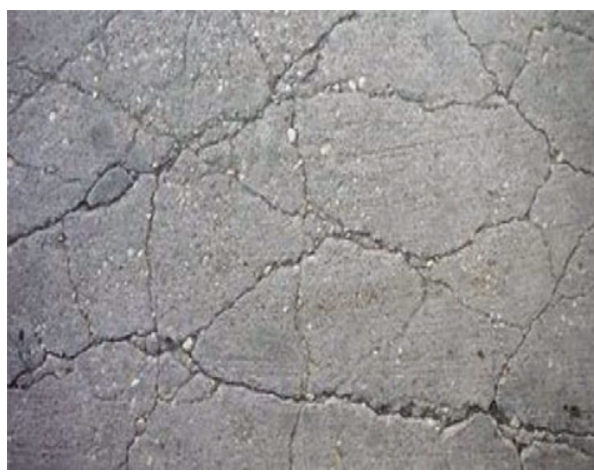

(a)

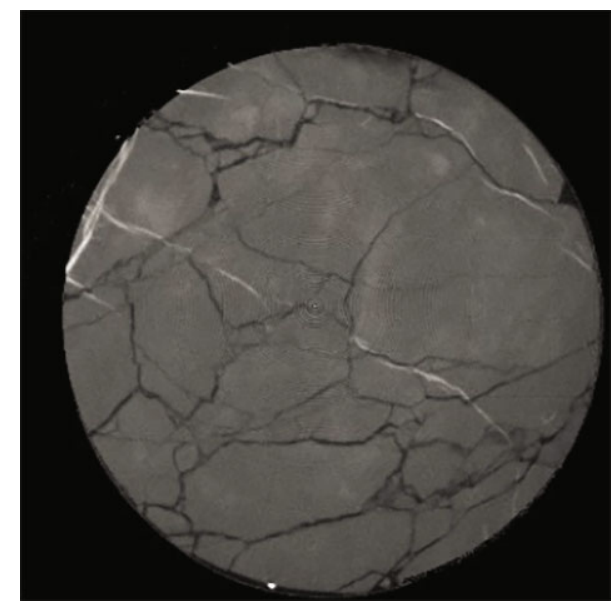

(b)

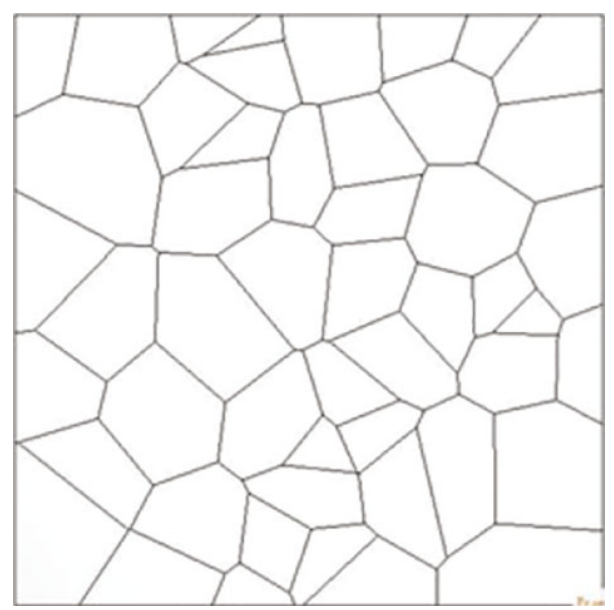

(c)

FIGURE 8: The proposal of the Voronoi structure for coal samples: (a) morphology of surface cracks for coal; (b) inner morphology of cracks presented by CT scanning; (c) example of Voronoi diagram. 


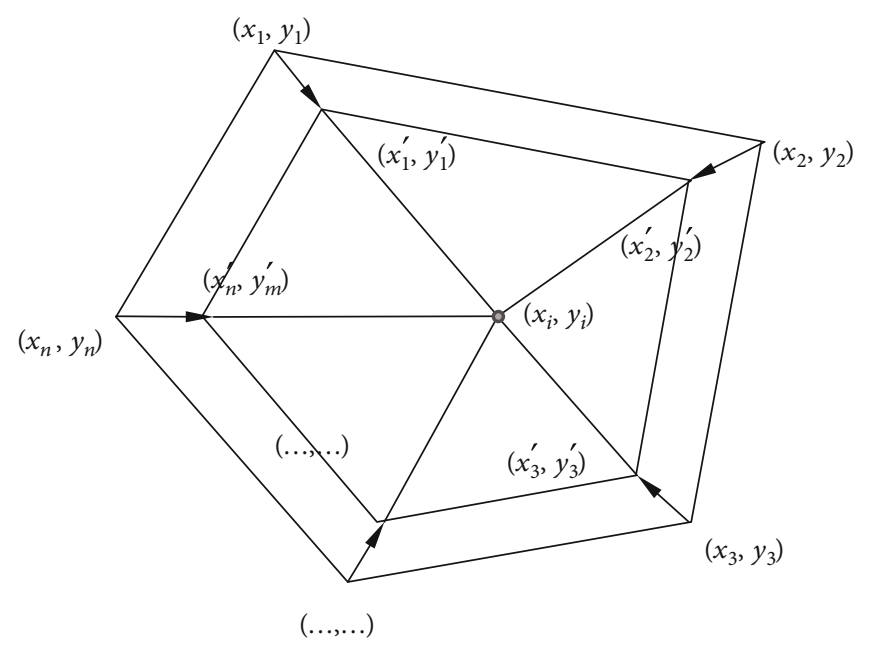

(a)

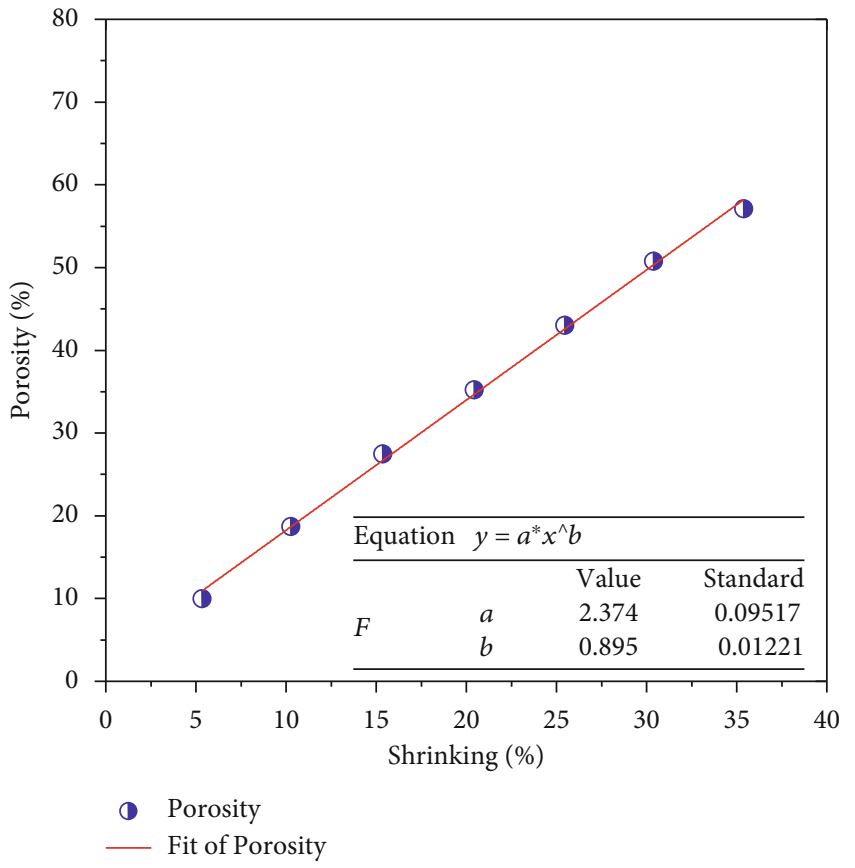

(b)

FIGURE 9: Shrinking process of the Voronoi polygon: (a) similar approach to generate inward contraction cracks; (b) changes in the overall shrinkage porosity.

TABLe 2: $D$ parameters of original adsorbed gases for selected Furong coal samples.

\begin{tabular}{lcccc}
\hline $\begin{array}{l}\text { Sample } \\
\text { number }\end{array}$ & $\begin{array}{c}\text { Temperature, } T \\
\left({ }^{\circ} \mathrm{C}\right)\end{array}$ & $\begin{array}{c}\mathrm{CH}_{4} \text { diffusion coefficient, } D \\
\left(\mathrm{~cm}^{2} * \mathrm{~s}^{-1}\right)\end{array}$ & $\begin{array}{c}\mathrm{CO}_{2} \text { diffusion coefficient, } D \\
\left(\mathrm{~cm}^{2} * \mathrm{~s}^{-1}\right)\end{array}$ & $\begin{array}{c}\mathrm{C}_{2} \mathrm{H}_{6} \text { diffusion coefficient, } D \\
\left(\mathrm{~cm}^{2} * \mathrm{~s}^{-1}\right)\end{array}$ \\
\hline TM1-5\# & 24.5 & $4.74 E-6$ & $2.36667 E-6$ & $6.98 E-6$ \\
TM1-4\# & 30 & $5.1 E-7$ & $5.23333 E-7$ & - \\
TM1-1\# & 35 & $1.93667 E-6$ & $1.37 E-6$ & $1.57667 E-6$ \\
TM2-1\# & 36.2 & $2.87667 E-6$ & $1.29667 E-6$ & $3.19333 E-6$ \\
TM2-2\# & 42 & $1.34667 E-6$ & $1.05667 E-6$ & $1.13 E-6$ \\
\hline
\end{tabular}

is the same. During the experiment, the gas can diffuse in any direction, because in the experiment of this paper, the coal rock is placed inside the thermal shrinkable sleeve of fluororubber, and the top and bottom are in contact with the cushion blocks. The cushion block and the rubber sleeve are bonded together with silica gel, so as to ensure that all the gases only can escape from the gas channel in the center of the cushion above the coal sample. In view of the above conditions, the boundary conditions of the established model have been shown in Table 3, and the geometric model and boundary conditions can be shown in Figure 10.

In the numerical simulation of the three temperatures in this paper, the geometric model used is the same. The following factors are mainly taken into account. Firstly, because the coal samples tested in this paper are collected from the same place, they have the same properties; secondly, in terms of porosity, the values of the three related coal samples are approximately equal. Thirdly, in order to reduce the vari- ables, the different effects of temperature on the diffusion process of adsorbed gas are studied more effectively. According to the above three reasons, this paper adopts the same geometric model for numerical simulation.

\section{The Influence of Temperature on the Gas Diffusion Process}

It is difficult to obtain the diffusion coefficient of gas in the pores of coal due to the complexity of the internal pore structure. Through experiments, Li et al. [36] and Wang et al. [37] pointed out that in the case of the same initial adsorption amount, during the process of heating diffusion at different temperatures, the diffusion amount at high temperature is always greater than that at low temperature, but the diffusion process at low temperature can reach the diffusion equilibrium more quickly. A rise in temperature will give methane molecules higher energy, enabling more molecules to be 
TABLE 3: Boundary and initial conditions of the established model.

\begin{tabular}{|c|c|c|}
\hline Initial value & $\begin{array}{c}\left.C\right|_{t=0}=C_{0} \\
C_{0}=e-6 \mathrm{~kg} / \mathrm{mm}^{2}\end{array}$ & Blue box area in the center of the model \\
\hline Boundary condition & $C_{b}=0$ & Boundary around coal sample (excluding air outlet) \\
\hline
\end{tabular}

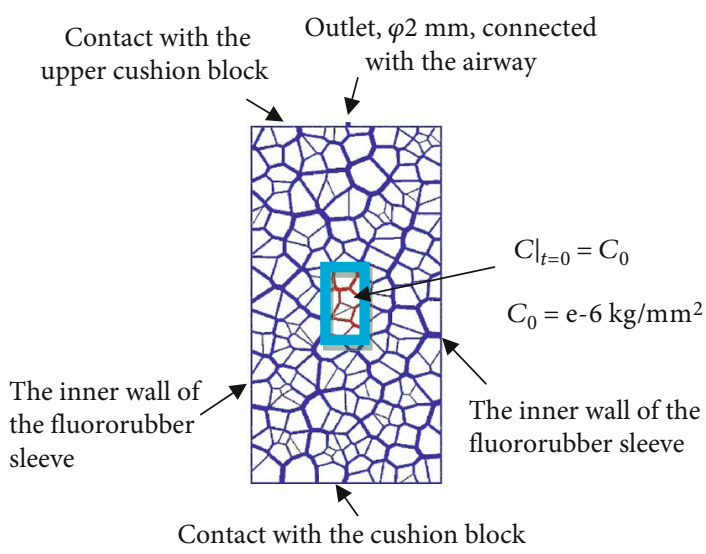

Figure 10: Geometry model of coal gas diffusion.

desorbed, and a rise in temperature will increase the diffusion coefficient, so that with a rise in temperature, methane molecules will spread faster and thus be able to spread out more gas molecules.

The above test mainly focuses on the diffusion behavior of free gas. However, the diffusion coefficient of adsorbed original gas in the raw coal matrix is completely different from the above results. It is known from Section 2.4 that the adsorption gas (methane, carbon dioxide, and methane) in raw coal fluctuates under constant temperature, as shown in Figures 3-7.

Within the Earth's interior, the temperature of the crust generally increases gradually with depth, with a temperature increase of $30^{\circ} \mathrm{C}$ for every $1 \mathrm{~km}$ increase in average depth. Calculated according to the surface temperature of $20^{\circ} \mathrm{C}$, the temperature range corresponding to $0 \sim 1 \mathrm{~km}$ is $20^{\circ} \mathrm{C} \sim 50^{\circ} \mathrm{C}$, and most mines in China are still below $1 \mathrm{~km}$. Therefore, the selection of numerical simulation temperature in this paper is also under the relatively common engineering temperature.

LS-DYNA is a fully functional geometric, material, and contact nonlinear program. It uses the Lagrange algorithm, ALE algorithm, and Euler algorithm; the program is based on an explicit algorithm and implicit solution. The program can perform nonlinear dynamic analysis. The diffusion process simulated in this paper is a nonlinear dynamic diffusion process. Although LS-DYNA does not have a diffusion module, it has a heat conduction module. Because of the similarity between the two equations, it can be used in the calculation of this simulation. The disadvantage of this program is that the modeling function is poor, so it needs to contact other software to carry out geometric modeling; this paper uses MATLAB to carry out geometric modeling. The model established in this paper is based on the Tyson polygon. Although the model is consistent in porosity, it is still different from the real pore structure.

In order to reproduce the process of methane diffusion in adsorbed gas in coal through numerical simulation, LSDYNA is used to simulate the methane diffusion process in raw coal at three temperatures $\left(24.5^{\circ} \mathrm{C}, 30^{\circ} \mathrm{C}\right.$, and $\left.42^{\circ} \mathrm{C}\right)$, and finally, a comparison is also made.

4.1. Numerical Simulation of the Diffusion Process at $24.5^{\circ} \mathrm{C}$. Figure 11 shows the concentration distribution cloud map corresponding to the eight time points of the methane diffusion process in coal under the condition of $24.5^{\circ} \mathrm{C}$, and the corresponding time points are $0 \mathrm{~s}, 30 \mathrm{~s}, 50 \mathrm{~s}, 90 \mathrm{~s}, 180 \mathrm{~s}$, $250 \mathrm{~s}, 400 \mathrm{~s}$, and $800 \mathrm{~s}$, respectively. The simulation is corresponding to sample FR1-5\#, the constant temperature is $24.5^{\circ} \mathrm{C}$, and the corresponding diffusion coefficient is $4.74 \mathrm{e}$ $-6 \mathrm{~cm}^{2} \mathrm{~s}^{-1}$. It can be seen from the diagram that the methane is concentrated in the center of the sample at the beginning of the calculation, and as the calculation continued, methane began to spread around evenly, the methane concentration around cracks slowly increased from zero and then decreased, and the methane concentrations in the center area are getting smaller. It reduced to $1.233 e-7 \mathrm{~cm}^{2} \mathrm{~s}^{-1}$ at $50 \mathrm{~s}$, decreased to $7.097 e-9 \mathrm{~cm}^{2} \mathrm{~s}^{-1}$ at $250 \mathrm{~s}$, and decreased to $9.419 e-12 \mathrm{~cm}^{2} \mathrm{~s}^{-1}$ at $800 \mathrm{~s}$. In the noncentral region, the concentration of gas increases first and then decreases, mainly because the concentration in the central region decreases continuously and the concentration gradient is reduced. In general, methane diffuses uniformly from the center to the outside of the porous medium. The gas in the central high concentration area gradually diffuses in the cracks around, and the concentration in the central area gradually decreases, while the concentration in other areas increases first and then decreases.

4.2. Numerical Simulation of the Diffusion Process at $30^{\circ} \mathrm{C}$. Figure 12 shows the concentration distribution cloud map corresponding to the eight time points of the gas diffusion process in coal at $30^{\circ} \mathrm{C}$, and the corresponding time points are 0 s, 30 s, 50 s, 90 s, 180 s, 250 s, 400 s, and 800 s. The simulation corresponds to sample FR1-4\#, the diffusion coefficient is $5.1 e-7 \mathrm{~cm}^{2} \mathrm{~s}^{-1}$, and the isothermal diffusion temperature is $30^{\circ} \mathrm{C}$. Also, it can be seen that at the beginning of the calculation, the methane is concentrated in the center of the sample; as the calculation continued, methane gradually spread along with fracture channels, methane concentration in the fracture around slowly increased from zero and then decreased, and the center area of the methane concentrations is getting smaller. It reduced to $1.148 e-7 \mathrm{~cm}^{2} \mathrm{~s}^{-1}$ at $50 \mathrm{~s}$, decreased to $5.712 e-9 \mathrm{~cm}^{2} \mathrm{~s}^{-1}$ at $250 \mathrm{~s}$, and decreased to $4.717 e-12 \mathrm{~cm}^{2} \mathrm{~s}^{-1}$ at $800 \mathrm{~s}$. It can be seen that the rate of 


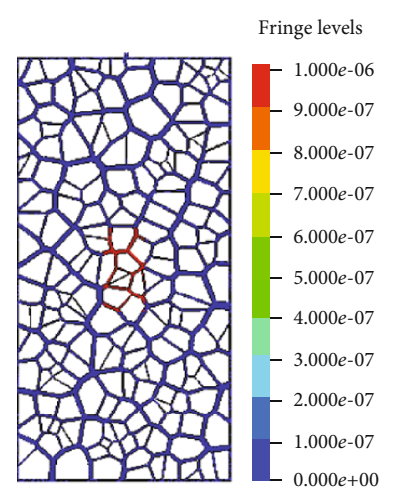

(a) $t=0 \mathrm{~s}$

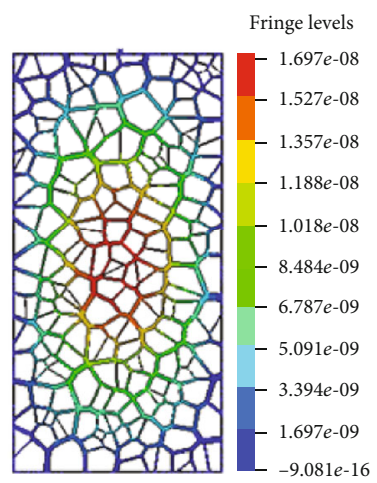

(e) $t=180 \mathrm{~s}$

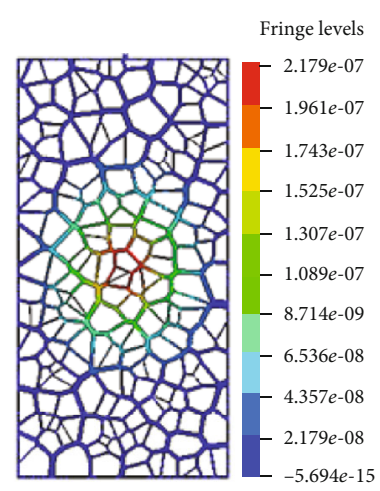

(b) $t=30 \mathrm{~s}$

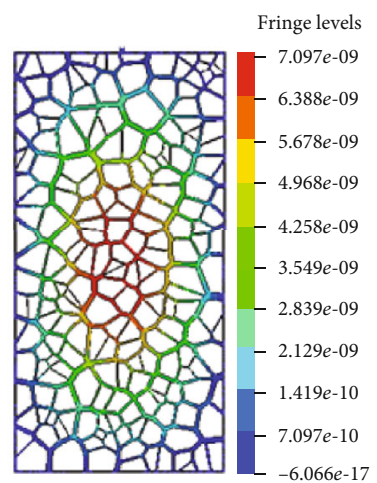

(f) $t=250 \mathrm{~s}$

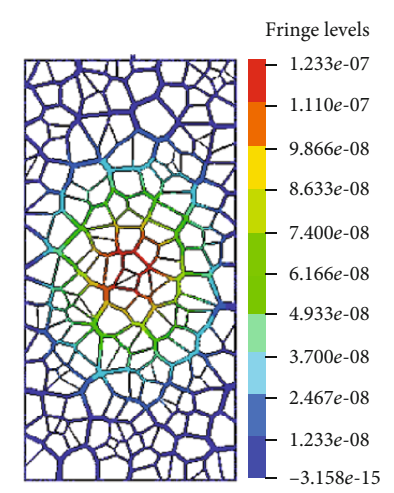

(c) $t=50 \mathrm{~s}$

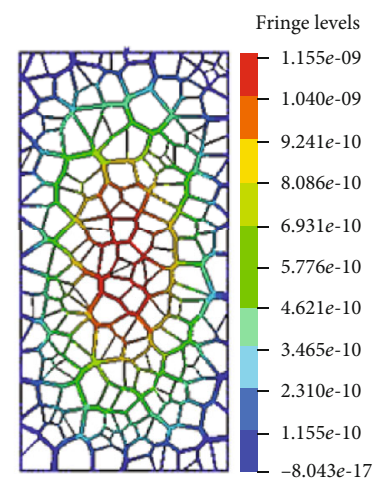

(g) $t=400 \mathrm{~s}$

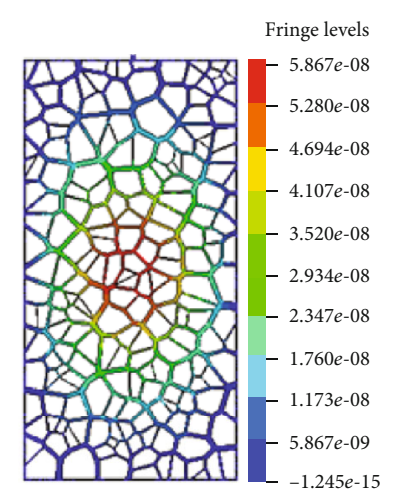

(d) $t=90 \mathrm{~s}$

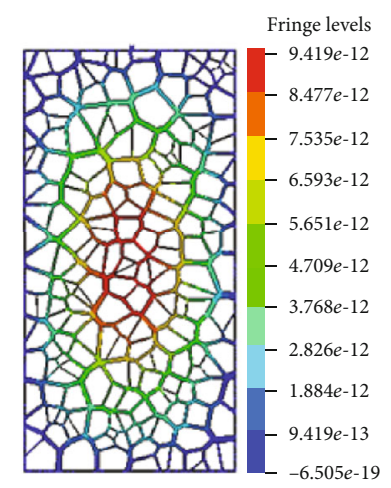

(h) $t=800 \mathrm{~s}$

Figure 11: Coal gas diffusion process at $24.5^{\circ} \mathrm{C}$.

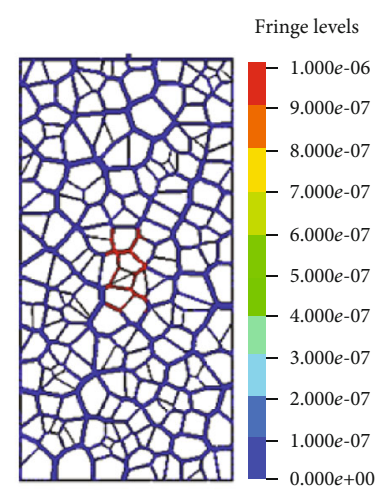

(a) $t=0 \mathrm{~s}$

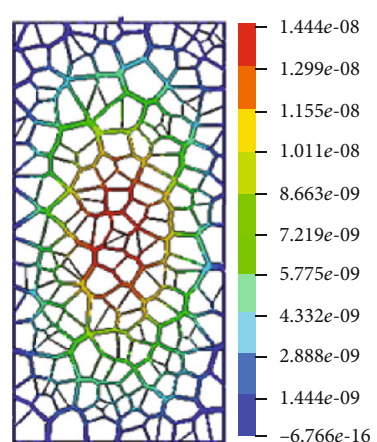

(e) $t=180 \mathrm{~s}$

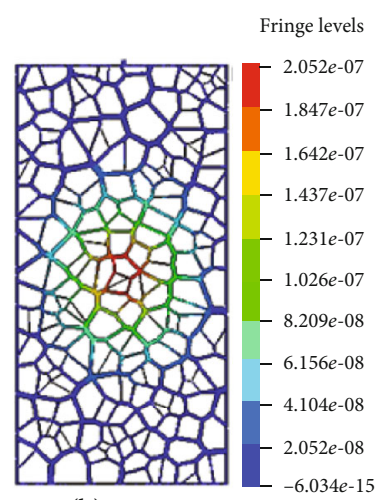

(b) $t=30 \mathrm{~s}$

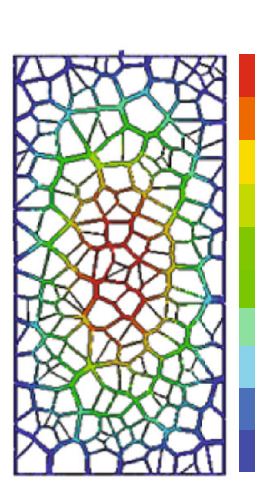

(f) $t=250 \mathrm{~s}$

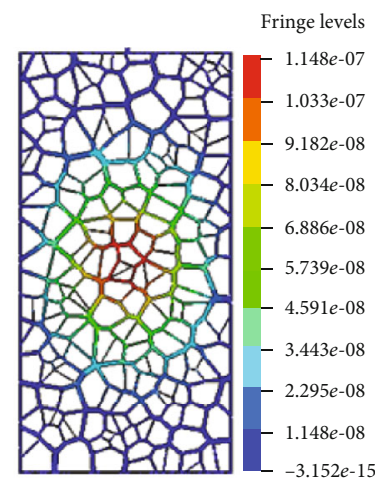

(c) $t=50 \mathrm{~s}$

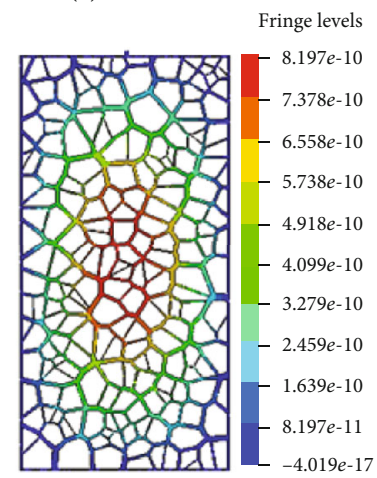

(g) $t=250 \mathrm{~s}$

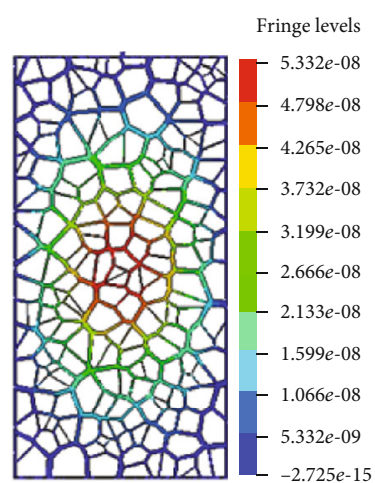

(d) $t=90 \mathrm{~s}$

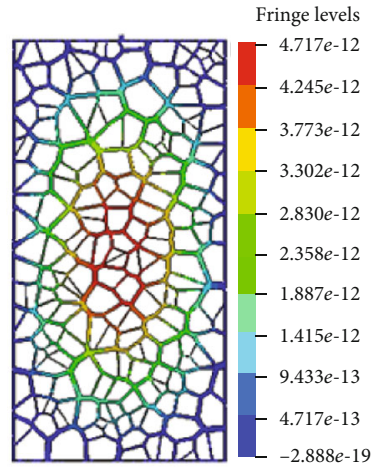

(h) $t=800 \mathrm{~s}$

Figure 12: Coal gas diffusion process at $30^{\circ} \mathrm{C}$. 


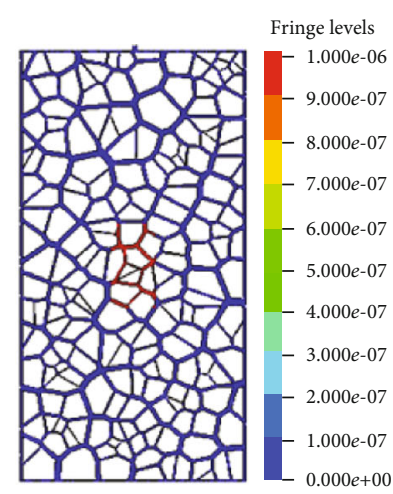

(a) $t=0 \mathrm{~s}$

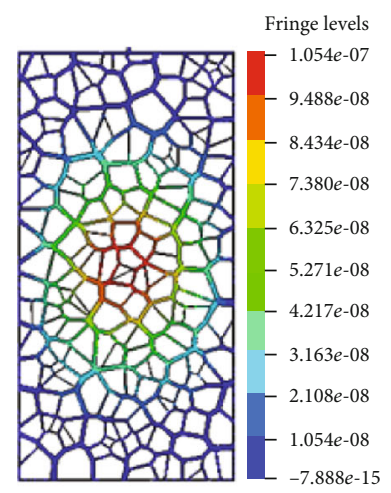

(e) $t=180 \mathrm{~s}$

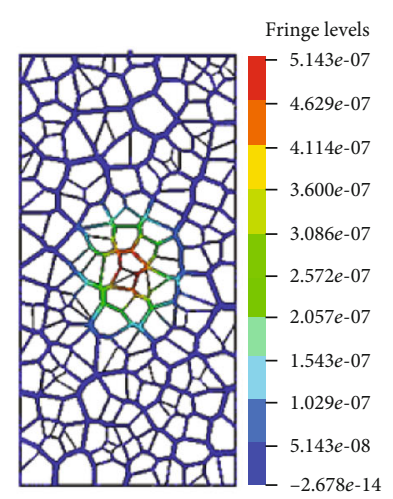

(b) $t=30 \mathrm{~s}$

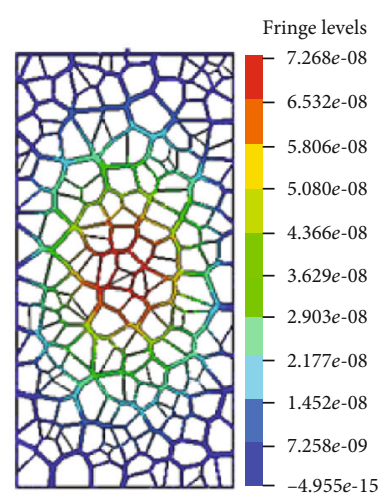

(f) $t=250 \mathrm{~s}$

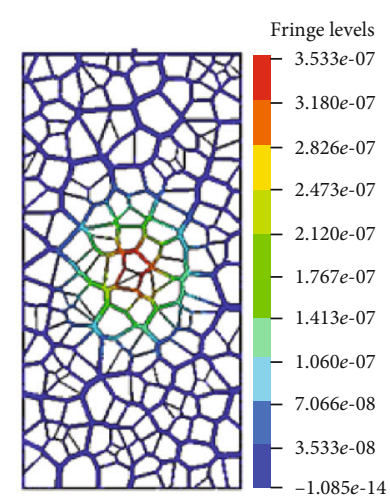

(c) $t=50 \mathrm{~s}$

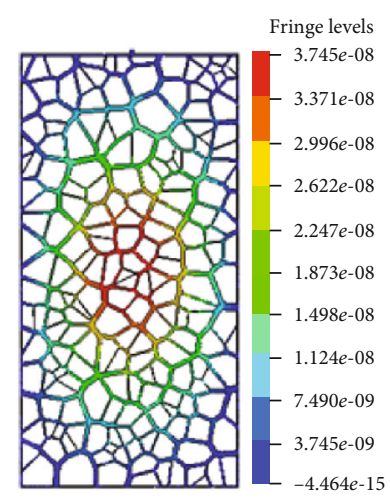

(g) $t=250 \mathrm{~s}$

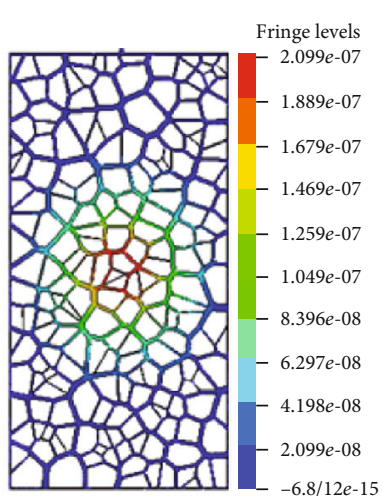

(d) $t=90 \mathrm{~s}$

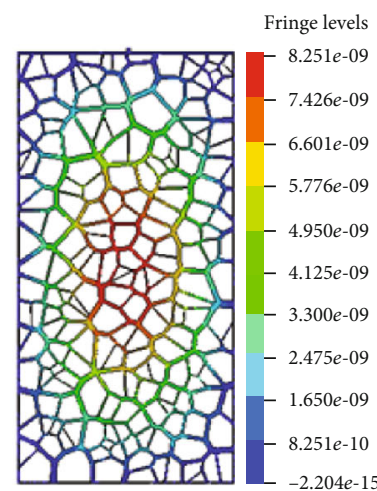

(h) $t=800 \mathrm{~s}$

Figure 13: Coal gas diffusion process at $42^{\circ} \mathrm{C}$.

reduction of the center area concentration under $30^{\circ} \mathrm{C}$ is lower than $24.5^{\circ} \mathrm{C}$. It also can be seen that at $50 \mathrm{~s}$, methane gas has spread to the left and right side walls, but the side wall was sealed with fluorine rubber packages, which cannot permit gas to pass; thus, it can be seen that at $90 \mathrm{~s}$, the spread of the methane began to shift from spreading evenly around to up and down spreading along the length direction. And for down boundary which is an enclosed area, the gas then eventually diffuses through the upper outlet. Similarly, in the noncentral region, the concentration of gas first increases and then decreases. Generally speaking, the diffusion process of methane in porous media uniformly spreads from the center to the outside, then spreads up and down, and finally spreads to the upper outlet. The gas in the central high concentration area gradually diffused in the cracks around, and the concentration in the central area gradually decreased, while the concentrations of other areas first increased and decreased.

4.3. Numerical Simulation of the Diffusion Process at $42^{\circ} \mathrm{C}$. Figure 13 shows the concentration distribution cloud map corresponding to 8 time points of the gas diffusion process in coal at $42^{\circ} \mathrm{C}$ (the same as Figures 11 and 12). This simulation corresponds to sample FR2-2\#, the corresponding diffusion coefficient is $1.34667 e-6 \mathrm{~cm}^{2} \mathrm{~s}^{-1}$, and the experimental temperature is $42^{\circ} \mathrm{C}$. It can also be seen that the law of methane diffusion is basically consistent with that of $24^{\circ} \mathrm{C}$ and $30^{\circ} \mathrm{C}$, except that the diffusion velocity is much slower, because the corresponding diffusion coefficient is smaller. The concentration of the central region decreases to $3.533 e$
$-7 \mathrm{~cm}^{2} \mathrm{~s}^{-1}$ at $50 \mathrm{~s}, 7.258 e-8 \mathrm{~cm}^{2} \mathrm{~s}^{-1}$ at $250 \mathrm{~s}$, and $8.251 e-$ $9 \mathrm{~cm}^{2} \mathrm{~s}^{-1}$ at $800 \mathrm{~s}$. It can be seen that the concentration of the central region decreases more slowly at $42^{\circ} \mathrm{C}$ than at $24.5^{\circ} \mathrm{C}$. In the noncentral area, the gas concentration still increased first and then decreased.

4.4. Result Analysis and Discussion. In theory, the diffusion coefficient of methane should rise with temperature below $60^{\circ} \mathrm{C}$. But in this article, the experiment results do not support that, because the experiments in this paper focused on desorption and diffusion of internal native adsorbed gas in the coal sample under isothermal conditions. The desorption amount differs from coal sample to sample; although all the coal samples are from the same position of the same coal mine, the existence of the original joint is still different; the other factors such as the process of drilling, cutting, and grinding will also change the internal state of real joints and pores and the adsorption state of gas. In addition, the influence of the experimental process should not be ignored, such as the difference in sealing and duration of the isothermal process; these are all important factors.

Figure 14 shows the numerical simulation results. The variation curve of methane gas concentration at the outlet over time shows that the higher the temperature is, the longer the peak time of the concentration will be and the higher the concentration at the outlet will be. Figure 15 shows the change curve of methane flow at the outlet over time. The methane gas produced by the isothermal process corresponding to $24.5^{\circ} \mathrm{C}$ and $30^{\circ} \mathrm{C}$ is approximately the same. At 


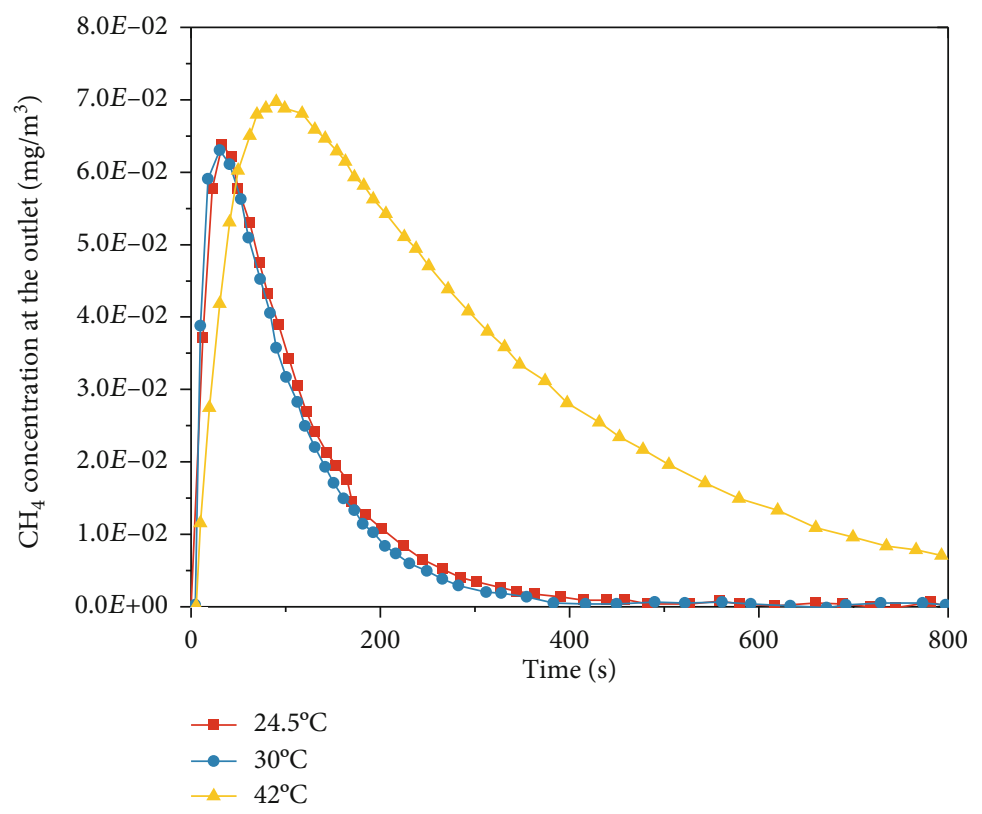

FIGURE 14: $\mathrm{CH}_{4}$ concentration at the outlet.

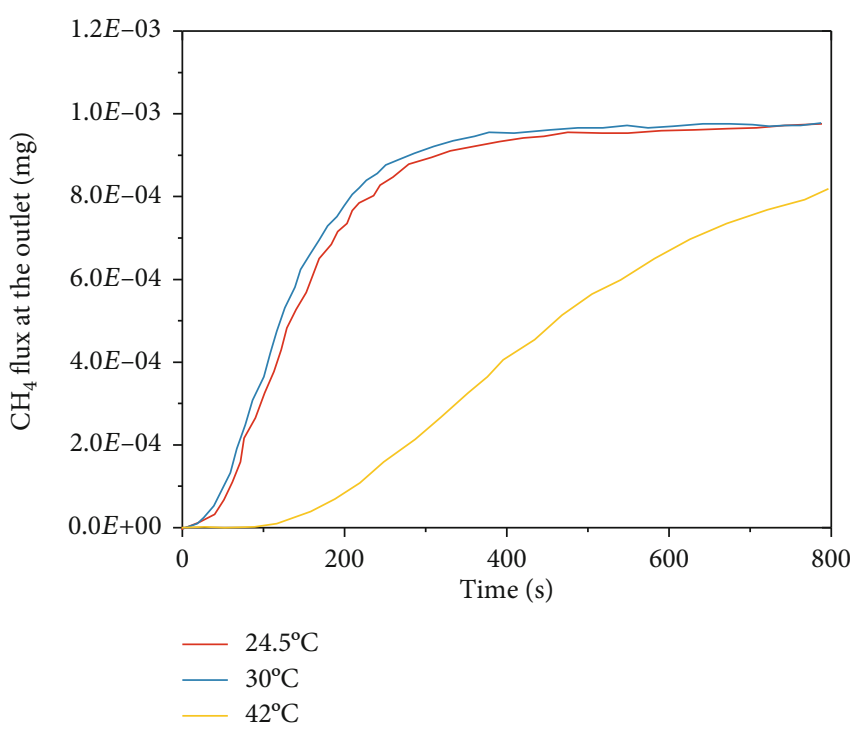

Figure 15: $\mathrm{CH}_{4}$ flux at the outlet.

$42^{\circ} \mathrm{C}$, due to the small diffusion coefficient, the amount of methane released at the end of the calculation is also smaller.

In this simulation, the diffusion and migration process of methane gas in the fracture channel is more visualized, but the desorption and adsorption process of the coal sample matrix itself is not considered, which is the research direction in the future.

\section{Conclusions}

In this paper, the desorption and migration of adsorbed gas in raw coal of the Furong mining area in Sichuan Province were studied experimentally by means of the $T-P$ coupling experiment system. The desorption and migration processes of adsorbed gas from raw coal under different isothermal conditions were analyzed, and the changes of relevant parameters (gas flow rate, gas pressure, and gas component concentration) were recorded and analyzed. The desorption and diffusion behavior of adsorbed gas in the isothermal process is obtained. In addition, based on the pore structure of coal samples, the equivalent geometric model of coal porous media was established. LS-DYNA was used to simulate the diffusion behavior of adsorbed gas in coal porous media, and the following main conclusions were obtained:

(1) Experiments were carried out on the isothermal desorption and diffusion process of Furong coal samples, and the variation rules of the escaping gas pressure, the escaping gas volume, and the component concentration were studied. It was found that the escaping gas volume would suddenly increase with higher positive gas pressure. The concentration of components increases first and then decreases. The slope of the volume of the escaped gas decreases with time and finally tends to a constant value

(2) Based on the CT scan image of the Furong coal sample, it was found that the joint distribution of the coal sample was similar to the distribution form of the Tyson polygon, a method to achieve the target porosity construction by using the contraction of the Tyson polygon was established, and a twodimensional joint pore model of the experimental coal sample was established

(3) Based on the consistency of mathematical expression between the transient heat conduction equation and Fick's second law and according to the porosity calculated by the mercury injection test, LS-DYNA was used to simulate the thermostatic laboratory 
experiment process of the three different experimental temperatures $\left(24.5^{\circ} \mathrm{C}, 30^{\circ} \mathrm{C}\right.$, and $\left.42^{\circ} \mathrm{C}\right)$. The results show that the higher the diffusion coefficient is, the faster the time to reach the diffusion equilibrium is and the shorter the time for the gas concentration to reach its maximum value is. The diffusion process of gas is a process of slowly moving from a highconcentration area to a low-concentration area, and it is also a process of coal sample self-balance. By comparing with the experimental process, the numerical process is in good agreement

\section{Data Availability}

The data are available and explained in this article, and readers can access the data supporting the conclusions of this study.

\section{Conflicts of Interest}

No conflict of interest exists in the submission of this manuscript.

\section{Authors' Contributions}

The manuscript is approved by all authors for publication.

\section{Acknowledgments}

This work was supported by the Technology Top Talent Support Project of the Department of Education of Guizhou Province ([2020]155, [2019]162, and [2017]307), the Research and Development Project of Guizhou University of Engineering Science (Grant No. G2018016), the Bijie City Science and Technology Plan Joint Fund Project ([2019]26), and the National Natural Science Foundation of China (Grant No. 41941018).

\section{References}

[1] S. Tao, Z. Pan, S. Tang, and S. Chen, "Current status and geological conditions for the applicability of CBM drilling technologies in China: a review," International Journal of Coal Geology, vol. 202, pp. 95-108, 2019.

[2] S. Tao, S. Chen, and S. Tang, "Coal seam porosity and fracture heterogeneity of marcolithotypes in the Fanzhuang Block, southern Qinshui Basin, China," Journal of Natural Gas Science and Engineering, vol. 66, pp. 148-158, 2019.

[3] S. Tao, S. Chen, D. Tang, Z. Xu, H. Xu, and L. I. Song, "Material composition, pore structure and adsorption capacity of low-rank coals around the first coalification jump: a case of eastern Junggar Basin, China," Fuel, vol. 211, pp. 804-815, 2018.

[4] B. Li, R. Bao, Y. Wang, R. Liu, and C. Zhao, "Permeability evolution of two-dimensional fracture networks during shear under constant normal stiffness boundary conditions," Rock Mechanics and Rock Engineering, vol. 54, no. 1, pp. 409-428, 2021.

[5] Z. G. Tao, C. Zhu, M. C. He, and M. Karakus, "A physical modeling-based study on the control mechanisms of negative Poisson's ratio anchor cable on the stratified toppling defor- mation of anti-inclined slopes," International Journal of Rock Mechanics and Mining Sciences, vol. 138, p. 104632, 2021.

[6] Q. X. Yu, Mine Gas Prevention and Control, China University of mining and technology press, Xuzhou, 1992.

[7] Z. Y. Wang, Y. P. Cheng, L. Wang et al., "Characterization of pore structure and the gas diffusion properties of tectonic and intact coal: implications for lost gas calculation," Process Safety and Environment Protection, vol. 135, pp. 12-21, 2020.

[8] Q. X. Meng, W. Y. Xu, H. L. Wang, X. Y. Zhuang, W. C. Xie, and T. Rabczuk, "DigiSim - an open source software package for heterogeneous material modeling based on digital image processing," Advances in Engineering Software, vol. 148, p. 102836, 2020.

[9] H. Huang, T. Babadagli, X. Chen, H. Z. Li, and Y. M. Zhang, "Performance comparison of novel chemical agents for mitigating water-blocking problem in tight gas sandstones," SPE Reservoir Evaluation \& Engineering, 2020, vol. 23, no. 4, pp. 1150-1158, 2020.

[10] Q. Yang and Y. Wang, "Theory of methane diffusion from coal cuttings and its application," Journal of Coal Science \& Engineering(China), vol. 3, pp. 89-96, 1986.

[11] D. Zhao, C. Zhang, H. Chen, and Z. Feng, "Experimental study on gas desorption characteristics for different coal particle sizes and adsorption pressures under the action of pressured water and superheated steam," Journal of Petroleum Science and Engineering, vol. 179, pp. 948-957, 2019.

[12] S. Chen, T. Yang, P. G. Ranjith, and C. Wei, "Mechanism of the two-phase flow model for water and gas based on adsorption and desorption in fractured coal and rock," Rock Mechanics and Rock Engineering, vol. 50, no. 3, pp. 571586, 2017.

[13] Y. J. Chen, D. D. Yang, J. Tang, X. Li, and C. Jiang, "Determination method of initial gas desorption law of coal based on flow characteristics of convergent nozzle," Journal of Loss Prevention in the Process Industries, vol. 54, pp. 222-228, 2018.

[14] Q. Wang, H. K. Gao, B. Jiang, S. C. Li, M. C. He, and Q. Qin, "In-situ test and bolt-grouting design evaluation method of underground engineering based on digital drilling," International Journal of Rock Mechanics and Mining Sciences., vol. 138, p. 104575, 2021.

[15] Q. Wang, Q. Qin, B. Jiang et al., "Mechanized construction of fabricated arches for large-diameter tunnels," Automation in Construction., vol. 124, p. 103583, 2021.

[16] F. Wang, Y. Liang, X. Li, L. Li, J. Li, and Y. Chen, "Orthogonal experimental study on multifactor conditions for gas desorption in coal," Advances in Civil Engineering, vol. 2019, Article ID 3028721, 2019.

[17] Y. Wang, B. Zhang, S. H. Gao, and C. H. Li, "Investigation on the effect of freeze-thaw on fracture mode classification in marble subjected to multi-level cyclic loads," Theoretical and Applied Fracture Mechanics, vol. 111, p. 102847, 2021.

[18] A. Li, F. Dai, Y. Liu, H. B. Du, and R. C. Jiang, "Dynamic stability evaluation of underground cavern sidewalls against flexural toppling considering excavation-induced damage," Tunnelling and Underground Space Technology, vol. 112, p. 103903, 2021.

[19] C. Zhu, M. He, M. Karakus, X. Zhang, and Z. Tao, "Numerical simulations of the failure process of anaclinal slope physical model and control mechanism of negative Poisson's ratio cable," Bulletin of Engineering Geology and the Environment, vol. 80 , no. 4 , pp. 3365-3380, 2021. 
[20] T. Gao, D. Zhao, C. Wang, and Z. Feng, "Energy variation in coal samples with different particle sizes in the process of adsorption and desorption," Journal of Petroleum Science and Engineering, vol. 188, p. 106932, 2020.

[21] W. Y. Lu, B. X. Huang, and X. L. Zhao, "A review of recent research and development of the effect of hydraulic fracturing on gas adsorption and desorption in coal seams," Adsorption Science \& Technology, vol. 37, no. 5-6, pp. 509-529, 2019.

[22] C. Zhu, M. He, M. Karakus, X. Zhang, and Z. Tao, "Numerical simulations of the failure process of anaclinal slope physical model and control mechanism of negative Poisson's ratio cable," Bulletin of Engineering Geology and the Environment, vol. 80, no. 4, pp. 3365-3380, 2021.

[23] H. Huang, T. Babadagli, H. Z. Li, K. Develi, and D. S. Zhou, “A visual experimental study on proppants transport in rough vertical fractures," International Journal of Rock Mechanics and Mining Sciences, vol. 134, p. 104446, 2020.

[24] X. Zhang, Z. Wang, Y. Sun, C. Zhu, F. Xiong, and Q. Tang, "Numerical simulation on heat transfer characteristics of water flowing through the fracture of high-temperature rock," Geofluids, vol. 2020, Article ID 8864028, 2020.

[25] K. Jin, Y. P. Cheng, T. Ren et al., "Experimental investigation on the formation and transport mechanism of outburst coalgas flow: implications for the role of gas desorption in the development stage of outburst," International Journal of Coal Geology, vol. 194, pp. 45-58, 2018.

[26] L. Li, Z. G. Sun, F. K. Wang, and K. Zhang, "Study on the gas desorption law and indicator influencing factors of fixed-size coal samples," Scientific Reports, vol. 9, no. 1, p. 17134, 2019.

[27] X. Li, Z. Li, T. Ren et al., "Effects of particle size and adsorption pressure on methane gas desorption and diffusion in coal," Arabian Journal of Geosciences, vol. 12, no. 24, 2019.

[28] Z. Q. Li, D. K. Wang, and D. Y. Song, "Influence of temperature on dynamic diffusion coefficient of $\mathrm{CH} 4$ into coal particles by new diffusion model," Journal of China Coal Society, vol. 40, no. 5, pp. 1055-1064, 2015.

[29] X. Tang, Z. Li, N. Ripepi, A. K. Louk, Z. Wang, and D. Song, "Temperature-dependent diffusion process of methane through dry crushed coal," Journal of Natural Gas Science and Engineering, vol. 22, pp. 609-617, 2015.

[30] T. Yang, P. Chen, B. Li, B. Nie, C. Zhu, and Q. Ye, "Potential safety evaluation method based on temperature variation during gas adsorption and desorption on coal surface," Safety Science, vol. 113, pp. 336-344, 2019.

[31] D. Zhao, Z. Feng, and Y. Zhao, "Laboratory experiment on coalbed-methane desorption influenced by water injection and temperature," Journal of Canadian Petroleum Technology, vol. 50, no. 7, pp. 24-33, 2011.

[32] S. Y. Liu, C. H. Wei, W. C. Zhu, and M. Zhang, "Temperatureand pressure-dependent gas diffusion in coal particles: numerical model and experiments," Fuel, vol. 266, p. 117054, 2020.

[33] Q. Xu, S. Q. Yang, Z. Q. Tang et al., "Optimum oxidation temperature of coal bed for methane desorption in the process of CBM extraction," Fuel, vol. 262, p. 116625, 2020.

[34] Z. C. Feng, D. Zhao, Y. S. Zhao, J. Zhao, and Z. Liu, "Effects of temperature and pressure on gas desorption in coal in an enclosed system: a theoretical and experimental study," International Journal of Oil Gas and Coal Technology, vol. 11, no. 2, pp. 193-203, 2016.

[35] A. W. Hatheway, "The complete ISRM suggested methods for rock characterization, testing and monitoring; 1974-2006,"
Environmental and Engineering Geoscience, vol. 15, no. 1, pp. 47-48, 2009.

[36] L. Zhi-qiang, D. Zhen-wei, and J. Guo-Xun, "Experimental study on gas diffusion characteristics from coal at different temperatures and their numerical simulation," China Safety Science Journal, vol. 22, no. 4, pp. 38-42, 2012.

[37] C. Wang, J. Zhang, and Y. Zang, "Time-dependent coal permeability: Impact of gas transport from coal cleats to matrices," Journal of Natural Gas Science and Engineering, vol. 2021, article 103806, 2021. 